\title{
Apresentação
}

\section{Espaços da Latinidade}

OSÉ VICENTE TAVARES-DOS-SANTOS * E MAÍRA BAUMGARTEN*"

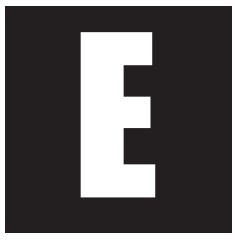

$\mathrm{m}$ seu décimo quarto número, Sociologias apresenta o dossiê Sociologia na (en) América Latina, ALAS, que revisita momentos significativos da Sociologia latino-americana. A partir de um significativo conjunto de textos que se referem uns aos outros como em um jogo de espelhos, queremos mostrar a enorme capacidade que a Sociologia, feita na América Latina, tem de fazer frente aos problemas sociológicos e às questões sociais do século XXI.

Esse retraçar de caminhos aponta possibilidades e potencialidades para avançar em direção daquilo que é um importante instrumento para a produção de conhecimentos sobre nossas sociedades no mundo atual: a criação de redes que nos permitam debater e encontrar instâncias e formas de cooperação entre investigadores, grupos e instituições, acadêmicas ou não; a busca da interação entre equipes de pesquisadores visando desenvolver e potencializar competências e conhecimentos; a atuação

\footnotetext{
"Doutor de Estado pela Université de Paris - Nanterre, Professor Titular do Departamento de Sociologia e do Programa de Pósgraduação em Sociologia do Instituto de Filosofia e Ciências Humanas da Universidade Federal do Rio Grande do Sul, Pesquisador do CNPq, Vice-Presidente da ALAS - Associação Latino-americana de Sociologia.

** Doutora em Sociologia, Professora do Departamento de Educação e Ciências do Comportamento da Fundação Universidade Federal de Rio Grande (FURG) e do Programa de Pós-graduação em Sociologia da Universidade Federal do Rio Grande do Sul (UFRGS). mayrab@terra.com.br
} 
transdisciplinar, fortalecendo espaços e instâncias de construção de ciências sociais que ajudem a aumentar a consciência crítica e desenvolver inovação e tecnologias sociais.

O exame das associações nacionais e regionais de Sociologia da América Latina, de sua estrutura, composição e transformações é algo pendente na história da disciplina. Com o artigo "La Asociación Latinoamericana de Sociología: una historia de sus primeros congresos" Alejandro Blanco reconstrói a história dos primeiros anos da Associação Latino-americana de Sociología (ALAS), buscando caracterizar seu contexto de emergência, suas principais características e seu papel na formação da sociologia da região.

Adrián Scribano, com o trabalho "Orígenes de la asociación latinoamericana de Sociologia: algumas notas a través de la visión de Alfredo Poviña", pretende mostrar, através da narração de Alfredo Poviña, a possível atmosfera dos primeiros congressos da ALAS. A partir das palavras do autor, Scribano busca colocar de modo preliminar algumas perguntas que possibilitem refletir sobre a gênesis da ALAS.

Luis Suárez Salazar nos fala da integração multinacional latino-americana e caribenha com o enfoque da prospectiva crítica e participativa. O autor realiza uma análise crítica do estado atual dos diferentes projetos de integração multinacional que se estão desenrolando na América Latina e no Caribe: "el Sistema de Integración Centroamericano (SICA), la Comunidad del Caribe (CARICOM), la Comunidad Andina de Naciones (CAN) y el Mercado Común del Sur (MERCOSUR)". A partir dessa análise o autor propõe algumas idéias relacionadas ao que denomina "un nuevo paradigma para la integración multinacional de América Latina y el Caribe" que seja capaz de confrontar a "integração coercitiva" que - através da ALCA e dos Tratados de Livre Comércio (TLC) - vem sendo impulsionada pelo governo dos Estados Unidos e também supere os limitados resultados do "regionalismo 
aberto" que a Cepal (Comissão econômica para a América Latina) vem impulsionando.

Lúcia Lippi Oliveira analisa as relações entre Brasil e América Latina, com seu artigo "Diálogos intermitentes: relações entre Brasil e América Latina". Segundo a autora, a América chamada latina viveu, desde a segunda metade do século XIX, obcecada pelo futuro e com dificuldades para consolidar suas comunidades nacionais. Diferentes correntes modernizadoras, entre elas o cientificismo, se defrontaram com correntes nacionalistas, preocupadas com a identidade, com o passado representado pelas culturas indígena e ibérica. Esse é o quadro histórico-cultural no qual são mencionadas as relações de identidade e de diferenciação entre o Brasil e demais países da América Latina. O artigo destaca a sociologia dos anos 1950 e 1960 como desdobramentos da matriz da Cepal, e a constituição de duas variantes do fazer sociológico: a concepção mertoniana e a mannheiniana. Por fim, apresenta o Centro Latino Americano de Pesquisa em Ciências Sociais (CLAPCS) e a Revista América Latina, atrelandoos à FLACSO, como espaços de atuação e circulação de uma elite de sociólogos mertonianos.

Com seu "Herencias y retos del conocimiento en América Latina" Raquel Sosa Elízaga aborda questões ligadas ao estudo dos determinantes sociais do conhecimento, ou de uma Sociologia dos modos de pensar, analisando algumas razões para o parco desenvolvimento desse campo na América Latina: entre elas a perda da memória histórica, o conservadorismo e a soberba acadêmica - que desconhece ou menospreza conhecimentos produzidos por seus colegas em outras partes da região, em outros períodos ou, ainda, em sítios alheios a seus próprios centros de pesquisa. Sosa avalia o peso das orientações dominantes e das perspectivas de constru- 
ção de um pensamento crítico na América Latina contemporânea.

Emir Sader parte de algumas questões: “...como um país "sem história" olha seu passado? De que maneira falar de uma geração que não recebeu herança e que ficou cortada das que vieram depois? Como reconstruir o itinerário da geração dos anos sessenta..." para nos falar de um período na história do Brasil e de como se produziu conhecimento sobre a sociedade nesse período, apresentando-nos em "Nós que Amávamos tanto o Capital" fragmentos para a história de uma geração.

Em "Contribuições da Sociologia na América Latina à imaginação sociológica: análise, crítica e compromisso social" José Vicente Tavares dos Santos e Maíra Baumgarten abordam o papel desempenhado pela Sociologia na análise dos processos de transformação das sociedades latino-americanas, no acompanhamento do processo de construção do Estado e da Nação, na problematização das questões sociais na América Latina. São analisados seis períodos na Sociologia na América Latina e no Caribe: I) a herança intelectual da Sociologia; II) a sociologia da cátedra; III) O período da "Sociologia Científica" e a configuração da "Sociologia Crítica"; IV) a crise institucional, a consolidação da "Sociologia Crítica" e a diversificação da sociologia; V) a sociologia do autoritarismo, da democracia e da exclusão; VI) a consolidação institucional e a mundialização da sociologia da América Latina (desde o ano de 2000), podendo-se afirmar que os traços distintivos do saber sociológico no continente foram: o internacionalismo, o hibridismo, a abordagem crítica dos processos e conflitos das sociedades latino-americanas e o compromisso social do sociólogo.

Lucio Oliver Costilla analisa várias características atuais das ciências sociais latino-americanas em paralelo ao desenvolvimento da América Latina nos últimos anos. $\mathrm{O}$ autor parte da idéia de que a combinação, contraditória no continente latino-americano, entre uma intelectualidade 
que tem um elevado nível cultural e a existência de movimentos sociais e políticos numa situação social explosiva, gera amplas possibilidades para o desenvolvimento da sociologia. A crise das ciências sociais acompanha estas mudanças significativas, na busca de novas perspectivas analíticas capazes de explicar o ritmo de mudanças contemporâneas. A rigor, no artigo, o autor busca demonstrar que o novo na sociologia latino-americana é, na verdade, um regresso ao pensamento crítico que a caracterizou no passado.

Edgar S. G. Mendoza trabalha com a perspectiva da Sociologia do conhecimento de Karl Mannheim para compreender o estado da arte dos estudos da pobreza na Guatemala, em um cenário compreendido entre 1980 a 2004. A pesquisa teve por objetivo realizar um balanço das tendências teóricas e metodológicas dos estudos nos últimos vinte anos.

Em seu artigo "El desarrollo de la sociología en el Perú. Notas introductorias" Julio Mejía Navarrete empreende uma síntese da evolução da Sociologia no Perú desde sua incorporação como cátedra universitária em 1896. O autor elabora um discurso que busca se vincular com os avatares próprios do desenvolvimento da modernidade no país e, ao mesmo tempo, apóia-se no debate teórico resultante do lento processo de institucionalização da disciplina e da emergência de uma maior consciência, nos últimos anos, acerca da pluralidade de paradigmas, perspectivas metodológicas e possibilidades interpretativas da realidade social.

Teresa Muñoz Gutiérrez aborda "Los caminos hacia una Sociología en Cuba. Avatares históricos, teóricos y profesionales". O texto nos traz um panorama da história da Sociologia em Cuba, elaborado a partir da combinação dos enfoques da História das Idéias e da História da Ciência. Empreendendo uma caracterização das etapas fundamentais que a Sociologia atravessou no país, a autora combina olhares: universal, regional e nacional, destacando as especificidades dos processos em Cuba, assim 
como seus correlatos na Europa e na América Latina.

Com o artigo "A Sociologia no Brasil: história, teorias e desafios", Enno Liedke Fo focaliza a história da sociologia no Brasil e as recepções de tradições sociológicas européias e norte-americana pela sociologia brasileira. As etapas e os períodos da evolução da Sociologia e de sua institucionalização como disciplina acadêmico-científica no Brasil são apresentados em seus traços principais, assim como a situação atual da sociologia nas universidades, os principais campos de pesquisa da sociologia brasileira e os novos temas e novas abordagens que vieram a ser propostos para a explicação e/ou compreensão da situação social brasileira.

Acreditamos que esse conjunto de reflexões sobre o Continente, com suas múltiplas questões, e a Sociologia que busca entendê-las, nos remete a um espaço próprio da nossa disciplina, um espaço de latinidade. Os debates que, em torno dele, estão a ocorrer, tem potencial para criar momentos de exercício da diversidade, de trocas solidárias e inclusivas, de crescimento e de criação de redes contra-hegemônicas.

Recebido: 05/07/2005 